\title{
Characteristics of advanced Parkinson's disease patients seen in movement disorder clinics - Australian results from the cross-sectional OBSERVE study
}

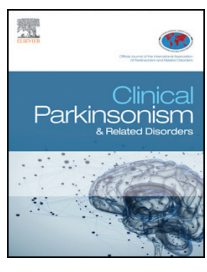

\author{
Andrew Evans ${ }^{\text {a,* }}$, Victor S.C. Fung ${ }^{\text {b,c }}$, John D. O'Sullivan ${ }^{\text {d,e }}$, Rick Stell ${ }^{\text {f }}$, Richard White ${ }^{\text {g }}$, David R. Williams ${ }^{\text {h }}$, \\ Samira Femia ${ }^{\mathrm{i}}$, Koray Onuk ${ }^{\mathrm{j}}$
}

a Movement Disorders Program, Royal Melbourne Hospital, Australia

b Movement Disorders Unit, Department of Neurology, Westmead Hospital, Australia

c Sydney Medical School, University of Sydney, Australia

d UQ Centre for Clinical Research, The University of Queensland, Australia

e Senior Visiting Neurologist Royal Brisbane \& Women's Hospital, Australia

${ }^{\mathrm{f}}$ Movement Disorders Clinic, Perron Institute, Australia

${ }^{g}$ Department of Neurology, Townsville Hospital, Australia

${ }^{\text {h }}$ Van Cleef Roet Centre for Nervous Diseases, Australia

${ }^{i}$ Therapeutic Area Lead, AbbVie, United States of America

${ }^{j}$ Study Designated Physician, AbbVie, United States of America

\section{A R T I C L E I N F O}

\section{Article history:}

Received 14 September 2020

Accepted 13 October 2020

Available online 17 October 2020

\section{Keywords:}

Parkinson's disease

Diagnosis

Advanced Parkinson's disease

Device assisted therapy

\begin{abstract}
A B S T R A C T
Objectives: To evaluate the proportion of Parkinson's disease (PD) patients identified as having advanced Parkinson's disease (APD) according to physician's judgement in Australia.

Methods: This cross-sectional, non-interventional observational study was performed in movement disorder clinics from 18 countries. Results from Australia are presented. Participants included consecutive adults with PD attending routine clinical visits, or inpatients, who could speak English. The primary outcome was the proportion of patients diagnosed with APD via physician judgement.

Results: 100 patients were recruited in Australia: 61.0\% (95\% CI 51.4-70.6\%) diagnosed with APD by physician judgement. Patients were $66.6 \pm 8.5$ years, $65 \%$ were male, were living at home $(97 \%)$, and diagnosed with PD for median 10.7 years ( $0-30.5$ years). Motor fluctuations were present in $68 \%$. For those with APD, referral was predominantly to enable access to device assisted therapies (DAT) (49\%), while for non-APD, referral was largely for diagnostic purposes (41\%). Patients had a median follow-up at the movement disorder clinic of 4.8 years for those with APD, or 3.6 years for non-APD. While $62 \%$ were eligible for DAT, only two-thirds of these received them. The most commonly used DAT was deep brain stimulation (64.3\%). There was fair agreement between physician's judgement and the APD criteria by Delphi method (Cohen's kappa) 0.325 (95\% CI 0.150-0.500) in the Australian subset.

Conclusions: The definition of APD requires refinement in order to facilitate greater agreement among movement disorder specialists. A third of APD patients eligible for DAT remain untreated. Better referral and education of patients with APD is needed.
\end{abstract}

\section{Introduction}

Parkinson's disease (PD) is an incurable, progressive, neurological disorder that develops gradually, and eventually may become severely disabling despite treatment [1,2]. The prevalence of PD ranges between 41 and 1903 cases per 100,000 and increases with age. Males are more likely to be affected than females [3]. The typical age of symptom onset is on average between 62 and 70 years, and the incidence peaks between 70 and 79 years [4]. However, currently there is limited data on the prevalence of advanced
PD (APD). Some previous epidemiological studies demonstrated approximately $10 \%$ of all PD patients to suffer from APD [4,5].

Current treatment algorithms for Parkinson's disease use a stepwise approach. Initially, patients are treated with oral dopaminergic therapies. As disease progresses, delays in gastric emptying, reduction in the brain's ability to make and store dopamine, impair the ability of oral dopaminergic therapies to provide adequate symptom control. In addition, the emergence of side effects such as motor fluctuations and dyskinesias can limit its usefulness [6-8]. With advancing disease, patients experience 'wearing off'.

\footnotetext{
* Corresponding author at: Movement Disorders Program, The Royal Melbourne Hospital, 300 Grattan Street, Parkville, VIC 3050, Australia.

E-mail address: Andrew.Evans@mh.org.au. (A. Evans).
} 
Wearing-off is the recurrence of parkinsonian symptoms including tremor, reduced dexterity or gait disturbance, or development of non-motor manifestations, usually taking place gradually over minutes (up to an hour) and usually bearing a close temporal relationship to the timing of antiparkinsonian medications (see Box 1). On-Off fluctuations are often predictable with the timing of oral medications. 'On' time is when PD medication is working well and symptoms are controlled best. 'Off' time is when PD medication is no longer working well and symptoms such as tremor, rigidity and slow movement re-emerge. With further progression, patients may experience, delayed 'on', unpredictable 'on-off' states, freezing, and fluctuations in blood pressure, behavior and sleep [9-11]. Once motor fluctuations have developed, increased therapy is required. Initially, this may include increased doses of levodopa, use of dopamine agonists, catechol-O-methyl transferase inhibitors or monoamine oxidase-B inhibitors. However, addition of these medications may be complicated by worsening dyskinesias or unsatisfactory improvement in 'off' periods [12], and challenges with patient adherence due to complexities in the drug regimen $[13,14]$.

Patients with APD are significantly limited in their activities, and while they may be able to walk and stand, they are often unable to complete dayto-day tasks, and usually cannot live alone. Swallowing becomes difficult, so treatment with multiple oral therapies is difficult. These patients can be assessed for a device assisted therapy (DAT), option which include apomorphine, deep brain stimulation or levodopa-carbidopa intestinal gel [15]. The goal of DAT in PD is sustained management aimed at reducing complications or shortfalls of oral therapies $[15,16]$.

One of the issues in PD management, however, is the appropriate recognition of advanced disease, and identification of patients who would benefit from DAT. Currently, there is no clear consensus on how to define the stages of PD. In the clinical setting, the Hoehn and Yahr scale (H\&Y scale) can be used to classify clinical stages of PD [17]. However, clinicians often rely on their clinical evaluation and historical interview to determine staging in PD because the $\mathrm{H} \& \mathrm{Y}$ scale is weighted heavily toward postural instability, symmetry and disability as the primary indices of disease severity. The H\&Y scale does not capture motor fluctuations, dyskinesia or nonmotor symptoms (NMS) that are often seen in PD patients [1]. Moreover, the time period reported for a patient to reach an advanced stage of PD varies greatly, as for some patients the latency from initial diagnosis of PD may be $>10$ years. Delayed diagnosis leads to delays in provision of DAT.

Determining what constitutes APD had been challenging in the past. A recent Delphi consensus study has attempted to address this, with the aim of improving not only identification of APD, but also to allow for improved patient management and care in this setting [17].

The OBSERVE-PD study of over 2600 patients at 128 movement disorder centres in 18 countries aimed to evaluate the proportion of patients

Box 1

Symptoms and definitions of Parkinson's disease.

'On' time is when PD medication is working well and symptoms are controlled best.

'Off' time is when PD medication is no longer working well and symptoms such as tremor, rigidity and slow movement re-emerge. Troublesome motor fluctuations occur when patients find that there is inconsistent effect of their PD medication leading to disability.

Troublesome dyskinesia occurs when patients find that there is inconsistent effect of their PD medication leading to abnormality or impairment of voluntary movement.

Wearing off is the perception of loss of mobility or dexterity, or the development of one of a number of non-motor manifestations, usually taking place gradually over minutes (up to an hour) and usually bearing a close temporal relationship to the timing of antiparkinsonian medications. identified as having APD according to physician judgement [18,19]. Secondary objectives included to describe the clinical characteristics of advanced vs non-advanced $\mathrm{PD}$ and to compare the proportion of patients with advanced disease compared to the Delphi consensus criteria [17]. Here we present results from the Australian subset of the previously published global study [19]. In - the present study, we performed additional post hoc analyses to explore patient characteristics that predict APD, and those likely to be referred for or treated with a DAT.

\section{Methods}

\subsection{Design and setting}

This observational study was a cross-sectional, non-interventional, multi-centre study, in movement disorder clinics in 18 countries across different geographical regions. A movement disorder clinic is an in-hospital multidisciplinary clinic that provides access to DAT for patient with APD. The results from the Australian cohort are presented here. One centre with a principal investigator who was a general neurologist (located in a regional setting) and five centres with movement disorder specialist neurologists (located in metropolitan centres) were included. These centres saw an average of 85 patients with PD per month, of whom approximately 8 were new patients. All patients were seen three or more times per year. The study was approved by local ethics committees and performed according to the International Conference on Harmonization and Good Clinical Practice requirements, in accordance with the principles of the Declaration of Helsinki.

\subsection{Participants}

Participants were recruited between February 2015 and January 2016. Included participants were consecutive adult male or female patients diagnosed with PD who were attending a routine clinical visit, or were inpatients at the participating clinical site, and who could speak English. Participants provided written informed consent. Potential participants were excluded if they were in an "off" state at the time of the visit, were participating in a clinical study, or if there was uncertainty around the diagnosis of PD.

\subsection{Variables and data sources}

Initially, the patient was screened against the inclusion and exclusion criteria, and then, prior to any other clinical assessments being performed, the treating clinician recorded the patients date of diagnosis with PD, whether they had motor fluctuations (and the period of time that these had occurred for), who referred the patient, and for what reason. Then the clinician was asked to decide whether the patient was 'in an advanced stage of disease according to your clinical judgement'. The patient's visit then continued, collecting information on demographics, caregiver support, education and occupation, PD history, PD treatment, comorbidities, patient- or clinician-reported outcomes (Unified Parkinson's Disease Rating Scale (UPDRS) II; UPDRS III; UPDRS IV; UPDRS V; Non Motor Symptom assessment Scale (NMSS), patient quality of life (PDQ-8)), along with results of an APD assessment. This assessment consisted of 11 questions developed by a panel of experts using a Delphi consensus (Table 2). A patient was classified as having APD if any one of the questions was answered 'yes'. All data were collected at a single patient visit.

The primary objective was to determine the proportion of PD patients identified as having APD according to the physician's judgement. Secondary objectives included to evaluate clinical characteristics of advanced versus non-advanced PD patients; to assess the percentage of APD patients considered for DAT; to explore referral practices for APD patients; to compare the percentage of APD patients identified in routine clinical practice by physician's judgment to the percentage of APD patients identified based on the Delphi method APD criteria. 


\subsection{Study size}

The sample size calculation was based on the overall study: a sample size of 2500 was chosen to assure that the two-sided $95 \%$ confidence interval for the primary endpoint would have a precision of $4.0 \%$ (i.e. the distance of the upper and lower limits of the CI from the observed difference would not exceed $2.0 \%$ ). No sample size calculation was performed on a country basis. Australian patients comprised 3.8\% of the overall 2615 patients recruited into the study.

\subsection{Statistical methods}

The time since diagnosis was calculated as the time in years between the date of the visit and the date of the initial PD diagnosis. Age was categorized as 65 years or less, and $>65$ years. Generally, analyses were descriptive and based on the full analysis set. Missing data were not imputed. Two-sided 95\% confidence intervals were provided for the primary endpoint and for selected secondary endpoints. Confidence intervals and $p$-values (two-sample $t$-test) were calculated for differences between advanced vs. non-advanced PD patients. Differences in diagnoses between physician judgement and Delphi criteria were compared using Cohen's Kappa. A post-hoc multivariate logistic regression was used to investigate the impact of potential prognostic factors on the primary endpoint (presence or absence of APD). Univariate logistic regression was used to identify factors to include in the model. Initial factors included PDQ-8 score, level of troublesome motor fluctuations, hours with 'off' symptoms, level of night time sleep disturbance, non-motor symptoms and number of daily oral levodopa doses. Factors with univariate $p<0.20$ were included in the multivariate model. Factors were removed in a backwards stepwise fashion until included variables all had $p<0.05$. Post-hoc pairwise correlations between quality of life score and level of troublesome motor fluctuations, hours with 'off' symptoms, level of night time sleep disturbance, non-motor symptoms and number of daily oral levodopa doses were calculated using Kendall's tau coefficient. The optimal cut-off for PDQ-8 score to identify APD was calculated using sensitivity and specificity analysis, with the clinician's opinion of whether the patient had APD as the reference variable, and PDQ-8 total score as the classifying variable. Youden's index was calculated to determine the optimal cut-off of PDQ-8 score [20]. The PDQ-8 score ranges from 0 to 100, with higher scores reflecting worse health. Analyses were conducted using SAS V9.2 and Stata MP v15 for Mac (StataCorp, Texas Station, US).

\section{Results}

\subsection{Participants}

There were 100 patients recruited in Australia: 61 with APD according to physician judgement, and 39 without APD (Table 1 ). The majority of patients were men, living at home with their partner or spouse. All patients had been referred to the movement disorder centre, either by their neurologist (54\%), general practitioner (35\%), geriatrician (6\%) or another specialist (5\%). For those with APD, referral was typically to enable access to DAT (49\%), while for those without APD, referral was more commonly for diagnostic purposes (41\%). Patients had a median follow-up at the movement disorder clinic of 4.8 years for those with APD, or 3.6 years for those without APD. Overall, $62 \%$ of patients $(62 / 100)$ were eligible for DAT, however, only $68 \%(42 / 62)$ of these were using a DAT, $25 \%$ (16/ $62)$ had no plans to commence DAT, and 7\% (4/62) had decided to start a DAT at that visit. For those who had initiated DAT, the most common was neurosurgical treatment (64\%).

3.2. Comparison between physician judgement and Delphi consensus diagnosis of $A P D$

According to the Delphi consensus, indicators for APD included moderate or severe motor fluctuations; more than two hours of 'off' time during the day; moderate or severe night time sleep disturbance; two or more hours of troublesome dyskinesia during the day; presence of non-motor fluctuations; presence of 'off' time at least every three hours; daily oral levodopa dosing of five times or more; moderate or severe limitation to activities of daily living; frequency of falling being most or all of the time; moderate or severe dementia and moderate or severe psychosis. [21] Australian agreement with the Delphi consensus criteria for diagnosis was poor (Table 2). Indeed, while $82 \%$ of patients were classified as advanced by the Delphi method, only $61 \%$ were classified as APD by physician judgement.

\subsection{Two questions to assess whether a patient is eligible for DAT}

Based on the Australian results of the OBSERVE study, the multivariate logistic regression (Table 3), and previous Australian guidelines [15] there are two questions that clinicians should use to determine whether a patient is eligible for DAT:

1. What is your quality of life (as assessed by the PDQ-8 score)?

2. What is the level of your troublesome motor fluctuations?

The multivariate logistic regression was statistically significant (LR $\chi^{2}$ 43.64; $p<0.0001, n=98$ ). Significant positive correlations between the PDQ-8 score and the level of troublesome motor fluctuations $(p<0.01)$, the hours that the patient has 'off' symptoms ( $p<0.001$ ), the level of night time sleep disturbance ( $\mathrm{p}<0.01$ ), the hours that the patient has troublesome dyskinesia ( $p=0.02$ ); and a significant negative correlation between the PDQ-8 score and not having non-motor symptoms $(\mathrm{p}<0.01)$ were found. There was no correlation between quality of life score and whether the patient had five times daily dosing of levodopa ( $p=0.16$ ).

The sensitivity and specificity analysis suggested a cut off score of 43.75 on the PDQ- 8 as being a reasonable balance between sensitivity (83\%) and specificity (66\%) for predicting APD, see also Fig. 1.

\subsection{Reasons patients choose not to have DAT}

For patient that were eligible for DAT, 16/62 (26\%) were not receiving DAT. Reasons included patient needs more time to decide $31.3 \%$, patient refusal $12.5 \%$, cognitive related issues $6.3 \%$, psychiatric related issues $6.3 \%$, comorbidities $6.3 \%$, lack of caregiver or family support $6.3 \%$, or 'other' undefined reasons $43.8 \%$,

\section{Discussion}

In the Australian subset of the OBSERVE study, the proportion of patients diagnosed with APD was $61 \%$. This was higher than that reported in the overall study of 2615 patients from 18 countries, where the proportion diagnosed with APD according to physician judgement was 51\% [18]. The difference may be due to referral patterns variations in Australia.

Australian patients can access three proven DAT for management of APD -reflected in the relatively higher proportion of APD patients treated in the specialised Australian centres participating in this study compared to the international cohort. However, gaps still remain in their application both within and outside these centres - a recent systematic evaluation of a rurally based movement disorders service for instance identified up to $19 \%$ of patients potentially eligible for DAT [22].

In both the Australian subset, and the overall cohort, the proportion of patients diagnosed with APD using the Delphi consensus criteria was higher ( $82 \%$ and $70 \%$, respectively) [18]. However, in the overall cohort, there was moderate agreement between the physician's judgement and the Delphi-consensus criteria (Cohen's kappa 0.441) compared to the Australian cohort, where it was fair (Cohen's kappa 0.325). Possible reasons for the lack of consensus between the two methods include: the inclusion of symptoms that typically reflect dopa-unresponsive disease features (such as falling, psychosis and dementia) in the Delphi criteria. Falling, psychosis and visual hallucinations are linked to advanced disease stages but can herald the onset of dementia and represent poor prognostic features in PD patients [23]. The Delphi criteria, which are a method of identifying APD, fail 
Table 1

Australian participant demographic, clinical history and clinician- and patient-reported outcomes.

\begin{tabular}{|c|c|c|c|}
\hline Demographic & $\begin{array}{l}\text { APD } \\
n=61\end{array}$ & $\begin{array}{l}\text { Non-APD } \\
n=39\end{array}$ & $\begin{array}{l}\text { Total } \\
n=100\end{array}$ \\
\hline Age, years, mean \pm SD & $66.2 \pm 8.8$ & $67.2 \pm 8.0$ & $66.6 \pm 8.5$ \\
\hline Male, n (\%) & $43(70.5 \%)$ & $22(56.4 \%)$ & $65(65.0 \%)$ \\
\hline \multicolumn{4}{|l|}{ Living arrangement, n (\%) } \\
\hline At home & $58(95.1 \%)$ & $39(100.0 \%)$ & $97(97.0 \%)$ \\
\hline Nursing home & $3(4.9 \%)$ & $0(0.0 \%)$ & $3(3.0 \%)$ \\
\hline \multicolumn{4}{|l|}{ Caregiver support, n (\%) } \\
\hline Yes & $38(62.3 \%)$ & $13(33.3 \%)$ & $51(51.0 \%)$ \\
\hline No & $19(31.1 \%)$ & $25(64.1 \%)$ & $44(44.0 \%)$ \\
\hline Not applicable & $4(6.6 \%)$ & $1(2.6 \%)$ & $5(5.0 \%)$ \\
\hline \multirow[t]{2}{*}{ Time since PD diagnosis, years, median (min, max) } & $n=59$ & $\mathrm{n}=39$ & $\mathrm{n}=98$ \\
\hline & $12.8(2.2,30.5)$ & $5.3(0,15.2)$ & $10.7(0,30.5)$ \\
\hline Motor fluctuations present, $\mathrm{n}(\%)$ & $54(88.5 \%)$ & $14(35.9 \%)$ & $68(68.0 \%)$ \\
\hline \multirow[t]{2}{*}{ Duration of motor fluctuations in those with motor fluctuations, years, median (min, max) } & $n=54$ & $n=14$ & $n=68$ \\
\hline & $8.0(1.5,24.0)$ & $4.5(0.0,7.0)$ & $7.0(0.0,24.0)$ \\
\hline Receiving treatment, n (\%) & $59(96.7 \%)$ & $37(91.9 \%)$ & $96(96.0 \%)$ \\
\hline \multicolumn{4}{|l|}{ Treatment, $\mathrm{n}(\%)$} \\
\hline Oral levodopa/carbidopa or benserazide & $56(91.8 \%)$ & $33(84.6 \%)$ & $89(89.0 \%)$ \\
\hline Oral dopamine agonist & $19(31.1 \%)$ & $18(46.2 \%)$ & $37(337.0 \%)$ \\
\hline Dopamine agonist patch & $2(3.3 \%)$ & $0(0.0 \%)$ & $2(2.0 \%)$ \\
\hline Apomorphine s.c. rescue injection & $1(1.6 \%)$ & $0(0.0 \%)$ & $1(1.0 \%)$ \\
\hline Catechol-o-methyltransferase inhibitors & $15(24.6 \%)$ & $3(7.7 \%)$ & $18(18.0 \%)$ \\
\hline Monoamine oxidase B inhibitors & $16(26.2 \%)$ & $13(33.3 \%)$ & $29(29.0 \%)$ \\
\hline Amantadine & $19(31.1 \%)$ & $3(7.4 \%)$ & $22(22.0 \%)$ \\
\hline Other & $12(19.7 \%)$ & $1(2.6 \%)$ & $13(13.0 \%)$ \\
\hline Missing & $2(3.3 \%)$ & $2(5.1 \%)$ & $4(4.0 \%)$ \\
\hline \multicolumn{4}{|l|}{ Number of PD treatments for those receiving treatment, $\mathrm{n}(\%)$} \\
\hline 1 & $16(27.1 \%)$ & $11(29.7 \%)$ & $27(28.1 \%)$ \\
\hline 2 & $18(30.5 \%)$ & $20(54.1 \%)$ & $38(39.6 \%)$ \\
\hline 3 & $15(25.4 \%)$ & $4(10.8 \%)$ & $19(19.8 \%)$ \\
\hline 4 & $7(11.9 \%)$ & $2(5.4 \%)$ & $9(9.4 \%)$ \\
\hline 5 & $3(5.1 \%)$ & $0(0.0 \%)$ & $3(3.1 \%)$ \\
\hline Eligible for DAT options, n (\%) & $52(85.2 \%)$ & $10(25.6 \%)$ & $62(62.0 \%)$ \\
\hline \multicolumn{4}{|l|}{ Status of DAT for those eligible, $\mathrm{n}(\%)$} \\
\hline Ongoing & $38(73.1 \%)$ & $4(40.0 \%)$ & $42(67.7 \%)$ \\
\hline Decision pending & $4(7.7 \%)$ & $0(0.0 \%)$ & $4(6.5 \%)$ \\
\hline Not using DAT treatment & $10(19.2 \%)$ & $6(60.0 \%)$ & $16(25.8 \%)$ \\
\hline \multicolumn{4}{|l|}{ Type of DAT treatment for those with ongoing treatment, $\mathrm{n}(\%)$} \\
\hline Neurosurgical treatment & $24(63.2 \%)$ & $3(75.0 \%)$ & $27(64.3 \%)$ \\
\hline Levodopa-carbidopa intestinal gel (LCIG) & $10(26.3 \%)$ & $1(25.0 \%)$ & $11(26.2 \%)$ \\
\hline Apomorphine sc infusion & $8(21.1 \%)$ & $1(25.0 \%)$ & $9(21.4 \%)$ \\
\hline \multirow[t]{2}{*}{ Duration of neurosurgical treatments, months, median (min, max) } & $\mathrm{n}=21$ & $\mathrm{n}=3$ & $\mathrm{n}=24$ \\
\hline & $42.0(0.0,180.0)$ & $27.0(1.0,68.0)$ & $39.0(0.0,180.0)$ \\
\hline \multirow[t]{2}{*}{ Duration of LCIG treatment, months, median (min, max) } & $\mathrm{n}=9$ & $\mathrm{n}=1$ & $\mathrm{n}=10$ \\
\hline & $17.0(1.0,75.0)$ & $0.0(0.0,0.0)$ & $12.5(0.0,75.0)$ \\
\hline \multirow[t]{2}{*}{ Duration of apomorphine treatment, months, median (min, max) } & $\mathrm{n}=8$ & $\mathrm{n}=1$ & $\mathrm{n}=9$ \\
\hline & $15.0(2.0,69.0)$ & $10.0(10.0,10.0)$ & $12.0(2.0,69.0)$ \\
\hline UPDRS II (Activities of daily living), mean \pm SD & $17.7 \pm 9.3$ & $9.8 \pm 6.6^{\mathrm{t}}$ & $14.6 \pm 9.2$ \\
\hline UPDRS III (Motor examination), mean \pm SD & $30.3 \pm 16.7$ & $19.5 \pm 14.7^{\S \S \S}$ & $26.1 \pm 16.8$ \\
\hline UPDRS IV Q32 (Dyskinesia), mean \pm SD & $1.2 \pm 1.1$ & $0.4 \pm 0.7 * * *$ & $0.9 \pm 1.0$ \\
\hline UPDRS V (Modified Hoehn and Yahr staging), mean \pm SD & $2.9 \pm 0.9$ & $2.0 \pm 0.8^{\dagger+1}$ & $2.6 \pm 1.0$ \\
\hline Total NMSS score, mean \pm SD & $71.6 \pm 47.8$ & $36.7 \pm 29.5^{\circ+}$ & $59.4 \pm 45.3$ \\
\hline PDQ-8 Total score, mean \pm SD & $35.4 \pm 19.3$ & $16.4 \pm 16.2^{\S \S \S \S}$ & $28.0 \pm 20.3$ \\
\hline
\end{tabular}

\footnotetext{
† Difference in group scores 7.90 (95\% CI 4.50, 11.30) $\mathrm{p}<0.0001$.

§§§ Difference in group scores $10.83(95 \%$ CI 4.33, 17.34) $\mathrm{p}=0.0013$.

$\square$ Difference in group scores $0.83(95 \%$ CI $0.44,1.21) \mathrm{p}<0.0001$.

thi Difference in group scores 0.86 (95\% CI 0.51, 1.21) p $<0.0001$.

t) Difference in group scores 34.99 (95\% CI 14.43, 55.56) $\mathrm{p}=0.0011$.

§§§ Difference in group scores 18.92 (95\% CI 11.44, 26.39) $\mathrm{p}<0.0001$.
}

to include factors such as caregiver support - which likely influence the decision to commence DAT in PD. It may also reflect a tendency of clinicians to more heavily weight the tangible and visible objective motor symptoms than the more qualitatively subjective non-motor symptoms.

In Australia, practical approaches to commencing DAT for patients with APD have been published [15]. This consensus based recommendation suggested DAT should be considered for patients when motor fluctuations cause disability or reduced quality of life; when response to treatment is inconsistent; when dyskinesias or motor fluctuations require frequent treatment adjustment without apparent benefit; or when levodopa is required four or more times daily. Perhaps the Delphi consensus weights too heavily the motor symptoms, without consideration for the impact of non-motor symptoms on the patient. Non-motor symptoms are reported to have a significant impact on the psychological well-being in patients with PD [24,25], and also influence their mortality [26].

Another important finding in this study was that there is a significant proportion of patients who are eligible for DAT for their APD that have either not yet commenced therapy, or who have refused therapy. This suggests that we need to allow patients sufficient time to decide whether or not they wish to receive DAT. This may require earlier patient education, so that once patients become eligible for DAT, they have had sufficient time to make this decision.

Our study has some limitations. Firstly, the study has a cross-sectional design. Secondly, movement disorder clinics included in this study were 
Table 2

Agreement between physician's judgement and Delphi method (Australia).

\begin{tabular}{|c|c|c|}
\hline Question & $\begin{array}{l}\text { Cohen's } \\
\text { Kappa }\end{array}$ & $95 \%-\mathrm{CI}$ \\
\hline $\begin{array}{l}\text { 1. What level of troublesome motor fluctuations does your } \\
\text { patient have? }\end{array}$ & 0.362 & $\begin{array}{l}{[0.225 ;} \\
0.499]\end{array}$ \\
\hline $\begin{array}{l}\text { 2. How many hours of the waking day does your patient have } \\
\text { OFF symptoms? }\end{array}$ & 0.129 & $\begin{array}{l}{[-0.055} \\
0.314]\end{array}$ \\
\hline $\begin{array}{l}\text { 3. What level of night time sleep disturbances does your } \\
\text { patient have? }\end{array}$ & 0.275 & $\begin{array}{l}{[0.111 ;} \\
0.439]\end{array}$ \\
\hline $\begin{array}{l}\text { 4. How many hours of the day with troublesome dyskinesia } \\
\text { does your patient have? }\end{array}$ & 0.201 & $\begin{array}{l}{[0.057} \\
0.345]\end{array}$ \\
\hline 5. Does your patient have NMS fluctuations? & 0.318 & $\begin{array}{l}{[0.145 ;} \\
0.491]\end{array}$ \\
\hline 6. Does your patient have "OFF" time at least every $3 \mathrm{~h}$ ? & 0.113 & $\begin{array}{l}{[-0.018} \\
0.244]\end{array}$ \\
\hline $\begin{array}{l}\text { 7. Does your patient have at least } 5 \text { times daily oral levodopa } \\
\text { dosing? }\end{array}$ & 0.216 & $\begin{array}{l}{[0.070} \\
0.362]\end{array}$ \\
\hline $\begin{array}{l}\text { 8. What level of limitation of ADL capacity does your patient } \\
\text { have? }\end{array}$ & 0.325 & $\begin{array}{l}{[0.186 ;} \\
0.465]\end{array}$ \\
\hline 9. What frequency of falls does your patient have? & 0.117 & $\begin{array}{l}{[0.040} \\
0.195]\end{array}$ \\
\hline 10. What degree of dementia does your patient have? & 0.082 & $\begin{array}{l}{[-0.025} \\
0.189]\end{array}$ \\
\hline 11. What degree of psychosis does your patient have? & 0.092 & $\begin{array}{l}{[0.023 ;} \\
0.161]\end{array}$ \\
\hline Overall APD classification by Delphi method & 0.325 & $\begin{array}{l}{[0.150} \\
0.500]\end{array}$ \\
\hline
\end{tabular}

selected based on whether DAT PD treatments could be offered, the percentage of patients with APD are likely higher than in randomly selected sites. On the other hand, the advantage is that the clinicians involved were highly experienced in case selection for APD. Further, selection bias was reduced by offering participation to consecutive patients attending a routine clinic visit.

Despite this, the strong message from the Australian OBSERVE dataset is that we should take into consideration the patient's quality of life, and their experience of troublesome motor fluctuations as indicators for their need for DAT.

\section{Conclusion}

Australian patients can access three proven DAT for management of APD -reflected in the relatively higher proportion of APD patients treated in the specialised Australian centres participating in this study compared to the international cohort. This dataset identified a third of PD patients eligible for DAT remain untreated, hence better referral and education of patients with APD is needed as well as a patient-centric approach to DAT in which the patient's quality of life is the starting point for discussion about

\section{Table 3}

Univariate and multivariate logistic regression for predictors of APD diagnosis in Australian patients.

\begin{tabular}{|c|c|c|c|}
\hline & $\begin{array}{l}\text { Univariate } \\
\text { p-value }\end{array}$ & $\begin{array}{l}\text { Multivariate odds } \\
\text { ratio }(95 \% \mathrm{CI})\end{array}$ & $\begin{array}{l}\text { Multivariate } \\
\text { p-value }\end{array}$ \\
\hline Quality of life (PDQ8 total score) & $\mathrm{p}<0.001$ & $1.20(1.08-1.32)$ & $\mathrm{p}<0.001$ \\
\hline $\begin{array}{l}\text { Level of troublesome motor } \\
\text { fluctuations (mild, moderate, } \\
\text { severe) }\end{array}$ & $\mathrm{p}<0.001$ & $7.47(2.24-25.0)$ & $\mathrm{p}=0.001$ \\
\hline $\begin{array}{l}\text { Hours of the waking day with 'off' } \\
\text { symptoms }(<2 \mathrm{~h}, 2-4 \mathrm{~h},>4 \mathrm{~h})\end{array}$ & $\mathrm{p}=0.192$ & & \\
\hline $\begin{array}{l}\text { Level of night time sleep disturbance } \\
\text { (mild, moderate, severe) }\end{array}$ & $\mathrm{p}=0.003$ & & \\
\hline $\begin{array}{l}\text { Hours of the day with troublesome } \\
\text { dyskinesia }(<2 \mathrm{~h}, 2-3 \mathrm{~h},>3 \mathrm{~h})\end{array}$ & $\mathrm{p}=0.006$ & & \\
\hline $\begin{array}{l}\text { Non-motor symptom fluctuations } \\
\text { (no, yes) }\end{array}$ & $\mathrm{p}=0.001$ & & \\
\hline $\begin{array}{l}\text { At least } 5 \text { times daily dosing of oral } \\
\text { levodopa (no, yes) }\end{array}$ & $\mathrm{p}=0.010$ & & \\
\hline
\end{tabular}

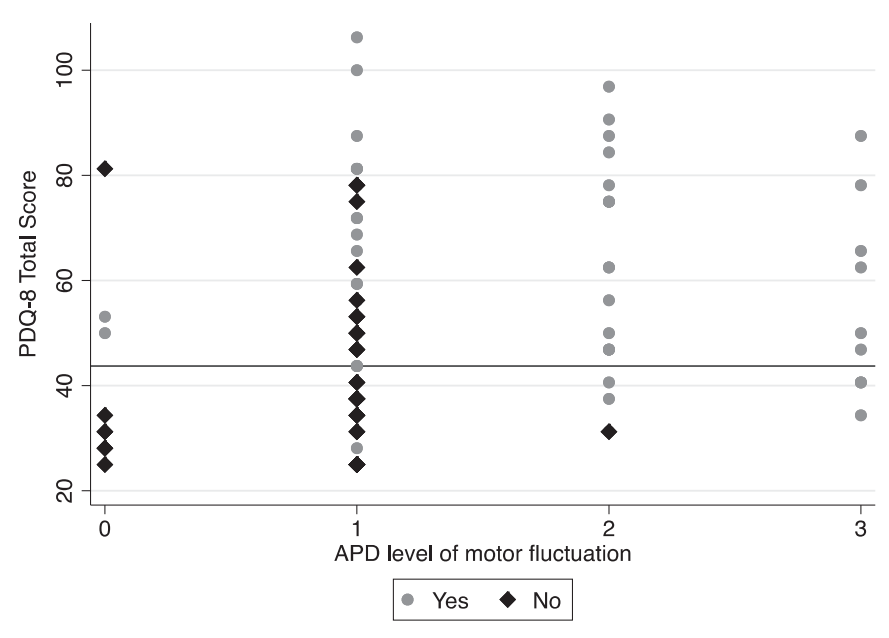

Fig. 1. Level of motor fluctuation reported on Delphi $(0=$ none, $1=$ mild, 2 $=$ moderate, 3 = severe) by PDQ- 8 Total score in patients categorized as having APD (circles) or not having APD (diamonds). Line shows PDQ-8 Total cutoff of 43.75 as suggested by sensitivity and specificity analysis.

DAT and patient's experience of troublesome motor fluctuations as an important indicator for likely benefit with DAT.

\section{Appendices}

Nil.

\section{Author declaration}

Parkinsonism \& Related Disorders is committed to proper scientific conduct and the protection of animal and human research subjects. Submission of this manuscript implies compliance with the following ethical requirements. Please affirm that you are representing all of the authors in stating compliance with these policies by checking the box at the end of this section.

1. Studies with human subjects must have been conducted in accordance with the Declaration of Helsinki. All persons must have provided informed consent prior to being included in the study.

2. Studies with animal subjects must have been conducted in accordance with the Guide for the Care and Use of Laboratory Subjects as adopted by the US National Institutes of Health and/or according to the requirements of all applicable local, national and international standards.

3. Protocols with animal or human subjects must have been approved by the relevant local committee(s) charged with ensuring subject protection. Studies that entail pain or distress will be assessed in terms of the balance between the distress inflicted and the likelihood of benefit.

4. The authors declare that the manuscript is original, that it is not being considered for publication elsewhere, and that it will not be submitted elsewhere while still under consideration for Parkinsonism \& Related Disorders or after it has been accepted by Parkinsonism \& Related Disorders.

5. All authors have seen and approved the manuscript in the form submitted to the journal. The authors declare that they have conformed to the highest standards of ethical conduct in the submission of accurate data and that they acknowledge the work of others when applicable.

6. All sources of financial support for the work have been declared in the Acknowledgements section of the manuscript. Any additional conflicts of interest must also be declared. Please include declarations of any consultancy or research funding received from relevant companies from three years prior to performance of the research until the time of manuscript submission. If the research is supported by internal funds, that should be stated as well. 
To indicate compliance with the preceding declaration and that you have obtained agreement from all of the authors of this paper to declare their compliance as well, please place an $\mathrm{x}$ here: _ $\mathrm{x}$.

In cases of uncertainty please contact an editor for advice.

\section{Declaration of competing interest}

The design, study conduct, and financial support for the study were provided by AbbVie. AbbVie participated in the interpretation of data, review, and approval of the publication. Andrew Evans has served on advisory boards for UCB, AbbVie, Britannia and Global Kinetics Corporation; honoraria for presentations for Stada, Lundbeck, Hospira, UCB, Teva, AbbVie and Global Kinetics Corporation; consultancy for CSL. Victor Fung receives a salary from NSW Health, has received unrestricted research grants from AbbVie and Merz, is on Advisory Boards and/or has received travel grants from AbbVie, Allergan, Ipsen, Merz, Stada, Teva and UCB, and receives royalties from Health Press Ltd. John O'Sullivan has served on advisory boards for AbbVie and STADA, has received honoraria for presentations from AbbVie, TEVA, Allergan \& Ipsen and has received research funding support from AbbVie, STADA, Pfizer, TEVA, Allergan \& Ipsen. Rick Stell has declared no conflict of interest. Richard White has received honoraria for presentations for AbbVie. David Williams has served on advisory boards for AbbVie and Allergan; honoraria for presentations for Stada, Lundbeck, Hospira, Teva and AbbVie; unrestricted research grants from AbbVie, Allergan, Ipsen. Samira Femia and Koray Onuk are employees of AbbVie and hold stock or stock options in AbbVie.

\section{Acknowledgements}

The authors thank Belinda Butcher BSc(Hons) MBiostat PhD CMPP of WriteSource Medical Pty Ltd, Sydney, Australia, for providing medical writing support, which was funded by AbbVie, Sydney, Australia in accordance with Good Publication Practice (GPP3) guidelines (http://www.ismpp.org/gpp3).

\section{References}

[1] M.M. Hoehn, M.D. Yahr, Parkinsonism: onset, progression, and mortality. 1967, Neurology 50 (2) (1998) 318 and 16 pages following.

[2] W. Poewe, P. Mahlknecht, The clinical progression of Parkinson's disease, Parkinsonism Relat. Disord. 15 (Suppl. 4) (2009) S28-S32.

[3] T. Pringsheim, N. Jette, A. Frolkis, T.D. Steeves, The prevalence of Parkinson's disease: a systematic review and meta-analysis, Mov. Disord. 29 (13) (2014) 1583-1590.

[4] A. Schrag, N. Quinn, Dyskinesias and motor fluctuations in Parkinson's disease. A community-based study, Brain 123 (Pt 11) (2000) 2297-2305.

[5] W. Muangpaisan, A. Mathews, H. Hori, D. Seidel, A systematic review of the worldwide prevalence and incidence of Parkinson's disease, J. Med. Assoc. Thail. 94 (6) (2011) 749-755.

[6] D. Nyholm, The rationale for continuous dopaminergic stimulation in advanced Parkinson's disease, Parkinsonism Relat. Disord. 13 (Suppl) (2007) S13-S17.

[7] G. Abbruzzese, P. Barone, U. Bonuccelli, L. Lopiano, A. Antonini, Continuous intestinal infusion of levodopa/carbidopa in advanced Parkinson's disease: efficacy, safety and patient selection, Funct. Neurol. 27 (3) (2012) 147-154.

[8] E. Dietrichs, P. Odin, Algorithms for the treatment of motor problems in Parkinson's disease, Acta Neurol. Scand. 136 (5) (2017) 378-385.
[9] Motor fluctuations and dyskinesias (diagnosis and management), Ann Indian Acad Neurol 14 (Suppl. 1) (2011) S13-5.

[10] P. Calabresi, M. Di Filippo, V. Ghiglieri, B. Picconi, Molecular mechanisms underlying levodopa-induced dyskinesia, Mov. Disord. 23 (Suppl. 3) (2008) S570-S579.

[11] G. Fabbrini, J.M. Brotchie, F. Grandas, M. Nomoto, C.G. Goetz, Levodopa-induced dyskinesias, Mov. Disord. 22 (10) (2007) 1379-1389 (quiz 1523).

[12] C. Trenkwalder, K.R. Chaudhuri, P.J. Garcia Ruiz, P. LeWitt, R. Katzenschlager, F. SixelDoring, T. Henriksen, A. Sesar, W. Poewe, D. Expert Consensus Group for Use of Apomorphine in Parkinson's, M. Baker, A. Ceballos-Baumann, G. Deuschl, S. Drapier, G. Ebersbach, A. Evans, H. Fernandez, S. Isaacson, T. van Laar, A. Lees, S. Lewis, J.C. Martinez Castrillo, P. Martinez-Martin, P. Odin, J. O'Sullivan, G. Tagaris, K. Wenzel, Expert Consensus Group report on the use of apomorphine in the treatment of Parkinson's disease-clinical practice recommendations, Parkinsonism Relat. Disord. 21 (9) (2015) 1023-1030.

[13] D. Grosset, A. Antonini, M. Canesi, G. Pezzoli, A. Lees, K. Shaw, E. Cubo, P. MartinezMartin, O. Rascol, L. Negre-Pages, A. Senard, J. Schwarz, K. Strecker, H. Reichmann, A. Storch, M. Lohle, F. Stocchi, K. Grosset, Adherence to antiparkinson medication in a multicenter European study, Mov. Disord. 24 (6) (2009) 826-832.

[14] D. Grosset, P.D.T.C.S.G. European, Therapy adherence issues in Parkinson's disease, J. Neurol. Sci. 289 (1-2) (2010) 115-118.

[15] D.R. Williams, A.H. Evans, V.S.C. Fung, M. Hayes, R. Iansek, T. Kimber, J.D. O'Sullivan, C.M. Sue, Practical approaches to commencing device-assisted therapies for Parkinson disease in Australia, Intern. Med. J. 47 (10) (2017) 1107-1113.

[16] P. Odin, K. Ray Chaudhuri, J.T. Slevin, J. Volkmann, E. Dietrichs, P. Martinez-Martin, J. K. Krauss, T. Henriksen, R. Katzenschlager, A. Antonini, O. Rascol, W. Poewe, C. National Steering, Collective physician perspectives on non-oral medication approaches for the management of clinically relevant unresolved issues in Parkinson's disease: consensus from an international survey and discussion program, Parkinsonism Relat. Disord. 21 (10) (2015) 1133-1144.

[17] A. Antonini, A.J. Stoessl, L.S. Kleinman, A.M. Skalicky, T.S. Marshall, K.R. Sail, K. Onuk, P.L.A. Odin, Developing consensus among movement disorder specialists on clinical indicators for identification and management of advanced Parkinson's disease: a multicountry Delphi-panel approach, Curr. Med. Res. Opin. 34 (12) (2018) 2063-2073.

[18] A. Fasano, L. Lopiano, B. Elibol, I.G. Smolentseva, K. Seppi, A. Takáts, K. Onuk, J.C. Parra, L. Bergmann, A. Yegin, Z. Pirtosek, 'Advanced' Parkinson's disease characteristics in clinical practice: results from the OBSERVE-PD study, a cross-sectional observational study of 2615 patients (P6.001), Neurology 88 (16 Supplement) (2017).

[19] A. Fasano, V.S.C. Fung, L. Lopiano, B. Elibol, I.G. Smolentseva, K. Seppi, A. Takats, K. Onuk, J.C. Parra, L. Bergmann, K. Sail, Y. Jalundhwala, Z. Pirtosek, Characterizing advanced Parkinson's disease: OBSERVE-PD observational study results of 2615 patients, BMC Neurol. 19 (1) (2019) 50.

[20] W.J. Youden, Index for rating diagnostic tests, Cancer 3 (1) (1950) 32-35.

[21] A. Antonini, P. Odin, L. Kleinman, A. Skalicky, T. Marshall, K. Sali, K. Onuk, Implemeting a Delphi panel to improve understanding of patient characteritics of advanced Parkinson's disease, 19th International Congress of Parkinson's Disease and Movement Disorders, San Diego, California, 2015.

[22] P. Farzanehfar, H. Woodrow, M. Braybrook, S. McGregor, A. Evans, F. Nicklason, M. Horne, Objective measurement in routine care of people with Parkinson's disease improves outcomes, NPJ Parkinsons Dis. 4 (2018) 10.

[23] P.A. Kempster, S.S. O'Sullivan, J.L. Holton, T. Revesz, A.J. Lees, Relationships between age and late progression of Parkinson's disease: a clinico-pathological study, Brain 133 (Pt 6) (2010) 1755-1762.

[24] A. Nicoletti, G. Mostile, F. Stocchi, G. Abbruzzese, R. Ceravolo, P. Cortelli, M.F. M. D’Amelio, G. De Pandis, C. Fabbrini, G. Pacchetti, A. Pezzoli, M. Tessitore, M. Canesi, Zappia, Factors influencing psychological well-being in patients with Parkinson's disease, PLoS One 12 (12) (2017), e0189682,

[25] B. Muller, J. Assmus, K. Herlofson, J.P. Larsen, O.B. Tysnes, Importance of motor vs. non-motor symptoms for health-related quality of life in early Parkinson's disease, Parkinsonism Relat. Disord. 19 (11) (2013) 1027-1032.

[26] D. Santos-Garcia, E. Suarez-Castro, J. Ernandez, I. Exposito-Ruiz, C. Tunas-Gesto, M. Aneiros-Diaz, T. de Deus-Fonticoba, M. Lopez-Fernandez, D. Nunez-Arias, Predictors of mortality in nondemented patients with Parkinson disease: motor symptoms versus nonmotor symptoms, J. Geriatr. Psychiatry Neurol. 31 (1) (2018) 19-26. 


\section{University Library}

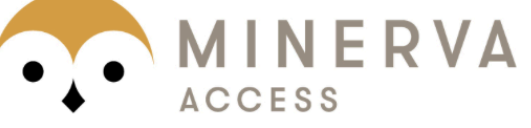

A gateway to Melbourne's research publications

Minerva Access is the Institutional Repository of The University of Melbourne

\section{Author/s:}

Evans, A;Fung, VSC;O'Sullivan, JD;Stell, R;White, R;Williams, DR;Femia, S;Onuk, K

Title:

Characteristics of advanced Parkinson's disease patients seen in movement disorder clinics

- Australian results from the cross-sectional OBSERVE study.

\section{Date:}

2021

\section{Citation:}

Evans, A., Fung, V. S. C., O'Sullivan, J. D., Stell, R., White, R., Williams, D. R., Femia, S. \& Onuk, K. (2021). Characteristics of advanced Parkinson's disease patients seen in movement disorder clinics - Australian results from the cross-sectional OBSERVE study.. Clin Park Relat Disord, 4, pp.100075-. https://doi.org/10.1016/j.prdoa.2020.100075.

Persistent Link:

http://hdl.handle.net/11343/287125

License:

CC BY-NC-ND 